\title{
GAMBARAN PERILAKU PEDAGANG SAYURAN DALAM PENGELOLAAN SAMPAH DI PASAR KEPUTRAN UTARA SURABAYA TAHUN 2020
}

Nandya Rachmayanti, Imam Thohari*, Hadi Suryono

Jurusan Kesehatan Lingkungan Poltekkes Kemenkes Surabaya

*Email korespondensi: imam1962@gmail.com

\begin{abstract}
ABSTRAK
Pasar Keputran Utara adalah pasar induk sayur-mayur terbesar di Surabaya yang menimbulkan beberapa permasalahan diantaranya yaitu kurangnya fasilitas tempat penampungan sampah, kurangnya kepedulian pedagang terhadap kebersihan lingkungan dan penumpukan sampah di sekitar kios/los menimbulkan bau yang tidak sedap, gangguan estetika, dan banyak lalat yang hinggap. Perlu adanya perbaikan perilaku pedagang guna terciptanya lingkungan pasar yang sehat dan pengukuran kepadatan lalat guna mengetahui tingkat kedapatan serta mencegah penularan penyakit. Penelitian ini bertujuan untuk menggambarkan perilaku pedagang sayuran dalam pengelolaan sampah di Pasar Keputran Utara Surabaya tahun 2020.

Penelitian ini menggunakan metode deskriptif dengan pendekatan cross sectional. Pengumpulan data dilakukan dengan wawancara, kuesioner dan pengukuran. Populasi dalam penelitian ini sebanyak 196pedagang sayuran dan diambil sampel sebanyak pedagang sayuran. Penelitian akan dilakukan di Pasar Keputran Utara Surabaya dengan variabel perilaku pedagang sayuran yang memiliki kategori baik cukup kurang dan pengukuran tingkat kepadatan lalat.

Hasil penelitian menunjukkan bahwa perilaku mendapatkan kategori cukup sebesar 46 orang $(70 \%)$ dan kategori kurang sebesar 20 orang (30\%). Hasil variabel pengukuran tingkat kepadatan lalat yang dikutip dari penelitian terdahulu yaitu 25,2 ekor/blockgrill dengan kategori sangat tinggi.

Disimpulkan dari hasil diatas bahwa perilaku yang kurang disebabkan oleh kurangnya fasilitas sarana prasana dalam pengelolaan sampah dan TPS yang kurang memadai. Disarankan kepada pedagang untuk menyediakan sarana tempat sampah di setiap los/kios agar tidak terjadi penumpukan sampah yang dapat menjadi tempat perkembangbiakan vektor penyakit.
\end{abstract}

Kata kunci : Perilaku Pedagang, Tingkat Kepadatan Lalat, Pasar

\section{PENDAHULUAN}

Pengertian Pasar Sehat menurut Keputusan Menteri Kesehatan Republik Indonesia Nomor: 519/Menkes/SK/VI/2008 tentang Pedoman Penyelenggaraan Pasar Sehat adalah kondisi pasar yang bersih, nyaman, aman, dan sehat melalui kerjasama seluruh stakeholder terkait dalam menyediakan pangan yang aman dan bergizi bagi masyarakat. Pasar sehat adalah pasar yang memiliki persyaratan kesehatan lingkungan yang meliputi lokasi, bangunan, sanitasi, perilaku hidup bersih dan sehat (PHBS), keamanan, dan fasilitas lain.

Menurut Keputusan Menteri Kesehatan Republik Indonesia Nomor: 519/Menkes/SK/VI/2008, Status kesehatan suatu populasi sangat ditentukan oleh kondisi tempat tersebut dan ketersediaan layanan kesehatan. Peranan pasar tradisional sangat penting dalam pemenuhan kebutuhan, terutama untuk golongan masyarakat menengah kebawah. Pasar tradisional juga dapat menjadi jalur untuk penyebaran penyakit seperti kolera, SARS, dan flu burung. Penyebaran penyakit ini dapat melalui sampah yang berserakan di lingkungan pasar yang dihasilkan dari kegiatan jual beli di pasar tersebut.

Sampah merupakan masalah yang umum terjadi di kota-kota besar di Indonesia. Sampah diidentifikasi sebagai salah satu faktor penyebab timbulnya dampak negatif bagi kegiatan perkotaan. Permasalahan sampah yang cukup rumit adalah permasalahan sampah pasar yang berjumlah relatif banyak dan sebagian 
terdiri dari sampah basah sehingga selama sampah menumpuk akan menjadi sumber pengotoran air dan tanah serta tempat perkembangbiakan vektor lalat, tikus, dan serangga yang mengakibatkan timbulnya bau serta gangguan estetika (Yulianto, 2016).

$$
\text { Salah satu faktor yang }
$$

mempengaruhi permasalahan pengelolaan sampah di pasar tradisional yaitu perilaku pedagang dalam pengelolaan sampah yang kurang baik meliputi pengetahuan, sikap, dan tindakan pedagang. Pasar menghasilkan jumlah sampah yang cukup besar yang berasal dari kios dan stan pedagang berupa sisa barang dagangan yang tidak terjual. Hal ini menyebabkan timbulnya dampak negatif terhadap lingkungan dan kesehatan bagi pedagang, pengunjung, maupun petugas pasar.

Pasar Keputran Utara adalah salah satu pasar tradisional di Kota Surabaya yang berada di wilayah cabang timur. Pasar Keputran merupakan pasar induk sayur-mayur terbesar di Surabaya yang menjual berbagai jenis sayuran yang dijajakan di setiap kios. Pasar Keputran Utara selalu buka bahkan saat pasar lain belum buka atau sudah tutup karena pasar ini digunakan untuk tempat membeli sayuran yang akan dijual oleh pedagang di pasar tradisional lain.

Berdasarkan hasil survei pendahuluan yang dilakukan pada hari Rabu, 23 Oktober 2019 pukul 13.00 WIBdi Pasar Keputran Utara Surabaya, dapat diketahui bahwa pedagang dan pembeli merasakan gangguan berupa bau yang tidak enak dan pemandangan yang kurang menyenangkan yang ditimbulkan oleh sampah yang dihasilkan oleh aktivitas di pasar. Hal ini disebabkan oleh pedagang yang membuang sisa barang dagangan yang sebagian besar berupa sampah sayuran disekitar tempat penjualan tanpa ditampung dahulu yang berakibat banyak lalat yang hinggap pada sampah maupun sayuran segar. Pedagang sayuran ini sebagian besar juga tidak memiliki tempat penampungan sampah yang memadai dan hanya dibuang pada kantung plastik besar yang berada di sekitar kios dan ada yang berserakan di pinggir jalan karena kantung plastik tidak bisa menampung kelebihan sampah.

\section{METODE PENELITIAN}

Jenis penelitian yang digunakan dalam penelitian ini adalah penelitian deskriptif yaitu suatu metode penelitian yang dilakukan untuk membuat gambaran atau deskripsi tentang suatu keadaan secara objektif(Notoatmodjo, 2018). Sedangkan metode pendekatan yang digunakan adalah cross sectional yaitu dilakukan sekali dalam kurun waktu tertentu yang bertujuan untuk menggambarkan perilaku pedagang sayuran dalam pengelolaan sampah di Pasar Keputran Utara Surabaya.

\section{HASIL PENELITIAN}

Berdasarkan Gambar 1 dibawah ini menunjukkan bahwa pengetahuan pedagang sayuran mengenai pengelolaan sampah terdapat 20 orang (30\%) dengan kategori baik, 35 orang(53\%) dengan kategori cukup, dan 11 orang (17\%) dengan kategori kurang.

Hal ini menunjukkan bahwa tingkat pendidikan terakhir pedagang mempengaruhi tingkat pengetahuan yang sejalan dengan penelitian Siahaan, dkk (2013) yang menyatakan bahwa semakin tinggi tingkat pendidikan maka semakin baik pula tingkat pengetahuan pedagang dalam pengelolaan sampah.

Tingkat pengetahuan pedagang sayuran dalam pengelolaan sampah di Pasar Keputran Utara Surabaya yang memiliki kategori cukup dan kurang akan mempengaruhi hidup perilaku hidup bersih dan sehat. Pengetahuan dengan kategori cukup dan kurang ini berkaitan dengan kepemilikan tempat sampah, penanganan sampah, pemilahan sampah, dan alat pengangkut sampah. Pedagang sayuran masih sangat bergantung pada pengelola pasar dan petugas kebersihan untuk membersihkan sampah hasil penjualan maupun sampah sayuran yang telah busuk.

Mengingat bahwa tingkat pengetahuan pedagang sayuran di Pasar Keputran Utara Surabaya masih terdapat pengetahuan yang baik sebanyak 20 orang (30\%), maka diperlukan upaya peningkatan pengetahuan dengan cara 
penyuluhan atau sosialisasi ke pedagang sayuran terutama tentang kepemilikan tempat sampah di tiap los/kios dan pemilahan sampah yang tentunya dapat meningkatkan kebersihan lingkungan, Dengan demikian peningkatan pengetahuan pedagang tentang pengelolaan sampah pasar yang baik dalam kehidupan sehari-hari penting sebagai upaya peningkatan perilaku hidup bersih dan sehat.

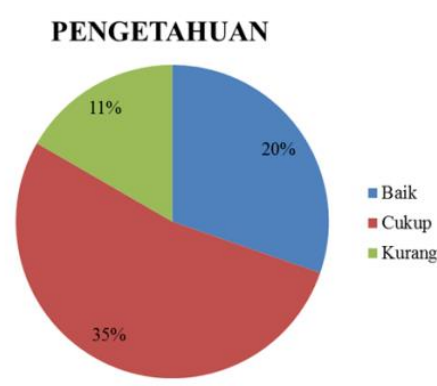

Gambar 1

Diagram Tingkat Pengetahuan Pedagang Sayuran dalam Pengelolaan Sampah di Pasar Keputran Utara Surabaya Tahun 2020

\section{Sikap Pedagang Sayuran dalam Pengelolaan Sampah}

Berdasarkan gambar 2 dibawah ini menunjukkan bahwa sikap pedagang sayuran mengenai pengelolaan sampah terdapat 53 orang $(80 \%)$ dengan kategori baik dan 13 orang (20\%) dengan kategori cukup.

Pedagang sayuran di Pasar Keputran Utara Surabaya yang memiliki sikap cukup sebanyak $20 \%$. Sebagian pedagang memiliki sikap cukup dalam hal peletakan tempat sampah dan pemilahan tempat sampah. Hal ini dikarenakan pedagang sayuran kurang peduli dalam hal peletakan tempat sampah yang seharusnya setiap kios harus memiliki tempat sampah yang diletakkan di dekat kios, karena sebagian besar pedagang sayuran menganggap bahwa tempat sampah jika diletakkan di dekat atau dalam kios akan mengganggu kegiatan jual-beli yang dapat menutup jalan dan mempersempit ruang, sehingga pedagang hanya membuang sampah di sekitar kios lalu pembuangan dan pengangkutan sangat bergantung pada petugas kebersihan. Kemudian, untuk pemilahan sampah basah (organik) dan sampah kering (anorganik) bagi pedagang sendiri sebagian besar berfikir jika kesulitan dan dianggap membuang waktu karena kegiatan jual beli telah menguras waktu dan tenaga sehingga langsung membuang sampah tanpa ada pemilahan terlebih dahulu.

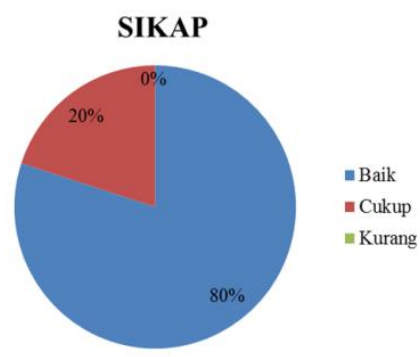

Gambar 2

Diagram Sikap Pedagang Sayuran dalam Pengelolaan Sampah di Pasar Keputran Utara Surabaya Tahun 2020

\section{Tindakan Pedagang Sayuran dalam Pengelolaan Sampah}

Berdasarkan gambar 3 dibawah ini menunjukkan bahwa tindakan pedagang sayuran mengenai pengelolaan sampah terdapat 20 orang (30\%) dengan kategori cukup dan 46 orang (70\%) dengan kategori kurang.

Pedagang sayuran di Pasar Keputran Utara Surabaya yang memiliki tindakan cukup sebanyak $30 \%$. Tindakan tersebut diwujudkan dalam pengumpulan dan pembuangan sampah minimal satu kali dalam sehari meskipun dalam hal pengangkutan sampah sangat bergantung pada petugas kebersihan mengingat bahwa pedagang telah memahami sampah organik yang dihasilkan banyak dan menimbulkan bau yang tidak sedap apabila dibiarkan dalam los/kios. 


\section{TINDAKAN}

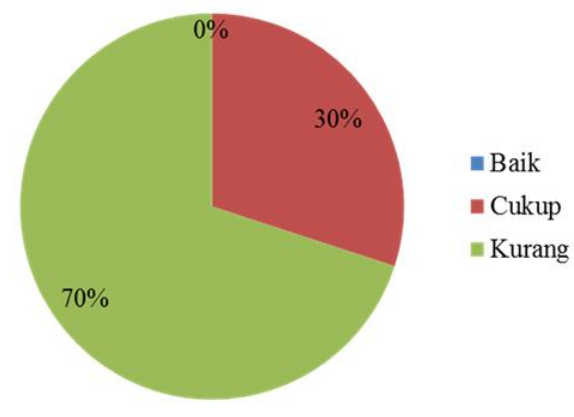

Gambar 3

Diagram Tindakan Pedagang Sayuran

dalam Pengelolaan Sampah di Pasar

Keputran Utara Surabaya Tahun 2020

\section{Perilaku Pedagang Sayuran dalam Pengelolaan Sampah}

Berdasarkan gambar 4 dibawah ini menunjukkan bahwa perilaku pedagang sayuran mengenai pengelolaan sampah terdapat 46 orang (70\%) dengan kategori cukup dan 20 orang (14\%) dengan katgori kurang. Perilaku sendiri dipengaruhi oleh tiga faktor utama yaitu faktor predisposisi, faktor pendukung, dan faktor penguat. Faktor predisposisi dapat dilihat dari pengetahuan dan sikap dimana faktor tersebut akan berperan dalam tindakan yang dilakukan. Pengetahuan yang dimaksud adalah bagaimana seharusnya yang dilakukan oleh pedagang dalam pengelolaan sampah yang baik, sehingga dapat mengambil sikap dengan tidak membuang sampah di sekitar lingkungan pasar dan tidak membiarkan sampah berceceran di sekitar los/kios serta menyediakan tempat sampah basah dan kering di setiap los/kios.

Pada penelitian Fauzan, dkk (2009) yang berlokasi di Pasar Induk Padang Panjang Kota Padang Panjang menunjukkan bahwa bentuk perilaku sebagian besar pedagang menyediakan alat kebersihan, rata-rata memilih diam untuk mengumpulkan sampah, rata-rata

membersihkan tempat dagang sebelum dan sesudah berjualan, sebagian membuang sampah di sekitar kios tetapi rata-rata sudah membuang sampah pada tempatnya, dan sebagian besar membayar retribusi pasar. Rata-rata mempunyai tempat sampah dan sebagian milik pedagang tetapi ada pula yang milik petugas, rata-rata tempat sampah dari tong plastic dan sebagian tempat sampah tertutup dan kedap air dan yang tidak memenuhi syarat akan diganti. Rata-rata ada yang belum dan sudah mengetahui peraturan terkait kebersihan, serta ada yang patuh dan tidak patuh lalu akan dikenai sanksi apabila melanggar.

\section{PERILAKU}

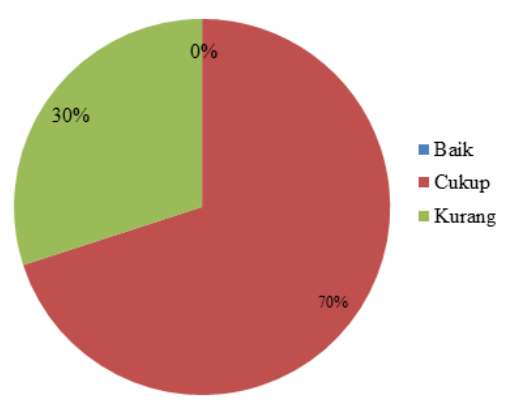

Gambar 4

Diagram Perilaku Pedagang Sayuran dalam Pengelolaan Sampah di Pasar Keputran Utara Surabaya Tahun 2020

\section{Pengukuran Tingkat Kepadatan Lalat}

Hasil pengukuran tingkat kepadatan lalat diambil dari penelitian terdahulu yang relevan dikarenakan terkendala oleh keterbatasan waktu dan adanya wabah COVID-19 sehingga tidak dapat melakukan pengukuran tingkat kepadatan lalat secara langsung di Pasar Keputran Utara Surabaya.

Berikut merupakan data sekunder tingkat kepadatan lalat yang diambil dari penelitian Noviyani, dkk (2019) : 
Tabel 5

Tingkat Kepadatan Lalat Berdasarkan Hasil Pengukuran Pada Sore Hari di Pasar Sentral Kota Kendari Tahun 2018

\begin{tabular}{cccccccccccc}
\hline $\begin{array}{c}\text { Pengukuran } \\
\text { Hari Ke- }\end{array}$ & \multicolumn{1}{c}{$\mathbf{1}$} & $\mathbf{2}$ & $\mathbf{3}$ & $\mathbf{4}$ & $\mathbf{5}$ & $\mathbf{6}$ & $\mathbf{7}$ & $\mathbf{8}$ & $\mathbf{9}$ & $\mathbf{1 0}$ & $\begin{array}{c}\text { Rata- } \\
\text { rata }\end{array}$ \\
\hline 1 & 9 & 11 & 9 & 7 & 8 & 9 & 5 & 6 & 5 & 4 & 9,2 \\
\hline 2 & 8 & 9 & 7 & 9 & 8 & 9 & 8 & 7 & 6 & 6 & 8,6 \\
\hline 3 & 9 & 6 & 6 & 5 & 5 & 8 & 8 & 6 & 5 & 4 & 7,4 \\
\hline 4 & 7 & 6 & 4 & 7 & 8 & 8 & 7 & 6 & 4 & 4 & 7,4 \\
\hline 5 & 8 & 9 & 10 & 4 & 6 & 6 & 4 & 7 & 4 & 5 & 8 \\
\hline 6 & 5 & 4 & 9 & 3 & 4 & 5 & 6 & 6 & 7 & 4 & 6,6 \\
\hline 7 & 9 & 8 & 7 & 7 & 4 & 6 & 5 & 2 & 3 & 4 & 7,4 \\
\hline 8 & 10 & 9 & 8 & 7 & 8 & 9 & 4 & 6 & 5 & 4 & 8,8 \\
\hline 9 & 8 & 6 & 6 & 7 & 6 & 5 & 4 & 3 & 5 & 4 & 6,6 \\
\hline 10 & 5 & 6 & 7 & 6 & 6 & 4 & 5 & 6 & 4 & 5 & 6,2 \\
\hline
\end{tabular}

Sumber : Noviyani, dkk (2019)

Tabel 6

Rekapitulasi Hasil Pengukuran Tingkat Kepadatan Lalat di Pasar Sentral Kota Kendari Tahun 2018

\begin{tabular}{ccccccccccccc}
\hline Waktu & \multicolumn{10}{c}{ Kepadatan Lalat Per Hari } & Rata- \\
\cline { 2 - 13 } Pengukuran & $\mathbf{1}$ & $\mathbf{2}$ & $\mathbf{3}$ & $\mathbf{4}$ & $\mathbf{5}$ & $\mathbf{6}$ & $\mathbf{7}$ & $\mathbf{8}$ & $\mathbf{9}$ & $\mathbf{1 0}$ & rata \\
\hline Sore & 9,2 & 8,6 & 7,4 & 7,4 & 8 & 6,6 & 7,4 & 8,8 & 6,6 & 6,2 & 25,2 \\
\hline
\end{tabular}

Sumber : Noviyani, dkk (2019)

\section{Kesimpulan}

1. Tingkat pengetahuan pedagang sayuran dalam pengelolaan sampah dengan kategori baik berjumlah 20 orang (30\%), kategori cukup berjumlah $35(53 \%)$, dan kategori kurang berjumlah 11 orang (17\%).

2. Sikap pedagang sayuran dalam pengelolaan sampah dengan kategori baik berjumlah 53 orang $(80 \%)$ dan kategori cukup berjumlah 13 orang (20\%).

3. Tindakan pedagang sayuran dalam pengelolaan sampah dengan kategori cukup berjumlah 20 orang $(30 \%)$ dan kategori kurang berjumlah 46 orang (70\%).

4. Perilaku pedagang sayuran dalam pengelolaan sampah dengan kategori cukup berjumlah 46 orang $(70 \%)$ dan kategori kurang berjumlah 20 orang (30\%).

5. Tingkat kepadatan lalat di Pasar Sentral Kota Kendari dengan ratarata 25,2 ekor/blockgrill dengan kategori sangat tinggi.

\section{Saran}

Bagi Pihak Perusahaan Daerah Pasar Surya dan Pengelola Pasar

1. Meningkatkan frekuensi pengangkutan sampah menjadi minimal $2 x$ dalam sehari agar sampah tidak menumpuk pada TPS.

2. Memberikan sosialisasi tentang pemilahan sampah organik dan anorganik.

3. Memberikan sosialisasi tentang cara pengelolaan sampah yang baik.

4. Melakukan pengawasan sanitasi pasar agar pasar tidak menjadi sumber penularan penyakit yang ditularkan melalui vektor.

5. Membangun TPS yang memenuhi persyaratan yang telah ditetapkan agar tidak menimbulkan penumpukan sampah.

6. Melakukan upaya pengendalian lalat untuk mengurangi kepadatan lalat.

\section{Bagi Pedagang}

Diharapkan sebaiknya menyediakan tempat sampah organik dan anorganik di masing-masing kios/los agar sampah tidak tercecer di sekitar lingkungan pasar. 


\section{DAFTAR PUSTAKA}

Fauzan, M., Ahyuni, \& Afdhal. (2009). Perilaku Pedagang dalam Membuang Sampah (Studi Kasus di Kawasan Pasar Induk Padang Panjang Kota Padang Panjang). Jurnal Buana, III(2). doi:https://doi.org/10.24036/stude nt.v3i2.427

Menteri Kesehatan Republik Indonesia. (2008). Keputusan Menteri Kesehatan Republik Indonesia Nomor: 519/Menkes/SK/VI/2008 Tentang Pedoman Penyelenggaraan Pasar Sehat.

Noviyani, E., La, Dupa., \& Yasnani, Y. (2019). Gambaran Kepadatan Lalat Di Pasar Basah Mandonga Dan Pasar Sentral Kota Kendari Tahun 2018. (Jurnal Ilmiah Mahasiswa Kesehatan Masyarakat), 4(1).
Siahaan, T., Dharma, S., \& MKM, T. A. (2013). Analisa Sistem Pengelolaan Sampah dan Perilaku Pedagang di Pasar Horas Kota Pematangsiantar Tahun 2013. Lingkungan dan Kesehatan Kerja, 3(2).

Yulianto, B. (2016). Partisipasi Pedagang Dalam Melakukan Pemilahan Sampah di Pasar Baru Kecamatan Tampan Kota Pekanbaru. Jurnal Kesehatan Komunitas, 3(2). 69-72 